\title{
Benefits of Kaizen to Business Excellence: Evidence from a Case Study
}

\section{Hassan Abdulmouti}

Department of Mechanical Engineering, Sharjah Men's College, Higher Colleges of Technology, Sharjah, UAE

\begin{abstract}
Kaizen contributed greatly to Japanese competitive success. It refers to the philosophy or practices that focus upon continuous improvement of processes in manufacturing, engineering, and business management. The improvement involves everyone from managers to workers. The improvements are usually accomplished without sophisticated techniques and entailing relatively little or no expense. The purpose of this paper is to elucidate the benefits of Kaizen to business excellence by presenting the results of implementing Kaizen principles at the Port Installed Options Center (PIOC) in Toyota, Saudi Arabia. Using relevant Kaizen tools including Toyota Production System (TPS), 5S and the seven Muda enables understanding of the system and identification of the critical problem areas. The Kaizen target was set after analyzing the problems and identifying the gap between the existing outdated system and the TPS. The main results of the Kaizen implementation can be summarized as: not having to invest in new facilities in order to meet the increase in demand in the market; increasing efficiency whilst reducing the manpower needed by $27 \%$ (from 349 to 275 installers); an increase in the annual output by $13 \%$ (from 188,000 to 212,400 vehicles); an improvement in the Associates Engagement Index (Q12) of 65\% (from 2.91 to 3.11); a potential inventory reduction due to the use of Kanban system with just in time production; a reduction in the number of vehicles damaged due to the control of the layout and flow by $76 \%$ (from 480 to 115 vehicles); and savings of about US $\$ 3.33$ million by not having to invest in new facilities nor to increase the number of installers needed to meet the increase in demand. All these improvements to the production line productivity were appreciated and acknowledged by Toyota Motor Corporation.
\end{abstract}

Keywords: Kaizen; Toyota Production System (TPS); Productivity; Business excellence; Management; Muda; $5 \mathrm{~S}$

\section{Introduction}

Many people ask the following common questions: 1) Why is Japan such an advanced and developed country? 2) What are the reasons for the success of Japanese companies? In fact, there are many reasons but Kaizen is one of the most important reasons in addition to Japanese culture itself. Kaizen is the Japanese word for "continuous improvement" or "change for the best". It refers to the philosophy or practices that focus upon continuous improvement of processes in manufacturing, engineering, and business management for various types of organizations and the healthcare sector. Kaizen has been adopted worldwide and it has become the central pillar for process improvement in many big companies, not only Toyota, where it has been adopted to define The Toyota Way (Toyota's DNA). In a simple definition, one can say that Kaizen activities aim to improve all functions of the business, through small steps, involving all employees. It is a collective effort that makes the process more efficient, effective, manageable, and adaptable. The improvements are usually accomplished at little or no expense and without sophisticated techniques or expensive equipment. Applying Kaizen to complex processes involves first breaking them down into their basic elements or sub-processes, and then improving them. The Kaizen Division in such companies has a role in educating employees on how to produce goods more efficiently with limited resources (manpower, material, space, machines and even processes). It is vital that all employees are involved in ongoing training and education in Kaizen activities in order to make continuous improvement for the organization, reduce costs, and increase efficiency in manpower and utilization of space, equipment and materials. Kaizen is a system of continuous improvement in quality, technology, processes, company culture, productivity, safety and leadership. Kaizen culture refers to the ability to step back from all activities, observe current processes and propose improvements or solutions to problems. The Toyota Way has been successfully applied in many dealerships and companies other than Toyota [1-15].
The purpose of this paper is to elucidate the benefits of Kaizen to business excellence by presenting the results of implementing Kaizen principles at Port Installed Options Center (PICO) in Toyota, Saudi Arabia. This paper is organized as follows: Section 2 presents the theoretical background, the definition and origin of Kaizen, the objective of the Kaizen division in any organization, Kaizen implementation principles, and the benefits of establishing a Kaizen Division. Section 3 presents and discusses the results of implementing the Kaizen principles in the case study, and the conclusion summarizes the main points. Using relevant Kaizen tools including Toyota Production System (TPS), 5S and the 7 Muda enables understanding of the system and identification of the critical problem areas. The Kaizen target was set after analyzing the problems and identifying the gap between the existing outdated system and the TPS. The main results of the Kaizen implementation can be summarized as: not having to invest in new facilities in order to meet the increase in demand in the market nor to increase the number of installers; increasing efficiency whilst reducing the manpower needed by $27 \%$ (from 349 to 275 installers); an increase in the annual output by $13 \%$ (from 188,000 to 212,400 vehicles); an improvement in the Associates Engagement Index (Q12) of $65 \%$ (from 2.91 to 3.11 ); a potential inventory reduction due to the use of Kanban system with just-in-time production; a reduction in the number of vehicles damaged due to the control of the layout and flow by $76 \%$ (from 480 to 115 vehicles); and savings of about US\$ 3.33 million by not having to invest in new facilities nor to increase the

*Corresponding author: Hassan Abdulmouti, Department of Mechanical Engineering, Sharjah Men's College, Higher Colleges of Technology, PO Box 7946 Sharjah, UAE, Tel: +97122066557; E-mail: habdulmouti@hct.ac.ae

Received February 09, 2018; Accepted March 15, 2018; Published March 21 2018

Citation: Abdulmouti H (2018) Benefits of Kaizen to Business Excellence: Evidence from a Case Study. Ind Eng Manage 7: 251. doi:10.4172/2169-0316.1000251

Copyright: ( 2018 Abdulmouti $\mathrm{H}$. This is an open-access article distributed under the terms of the Creative Commons Attribution License, which permits unrestricted use, distribution, and reproduction in any medium, provided the original author and source are credited. 
number of installers needed to meet the increase in demand. All these improvements to the production line productivity were appreciated and acknowledged by Toyota Motor Corporation.

\section{Theoretical Background}

\section{Kaizen and its important principles}

Kaizen in Japanese characters (Kanji) is improve and in hiragana is something. The first kanji character, Improvement in hiragana or KAI in Romaji), means change, search, examine, while the second kanji character, good (Hmm in hiragana or ZEN in Romaji), means good or better. Hence, Kaizen is the ability to make a change for the better after analysis and discussion of new ideas.

The Kaizen spirit has its origins in the history of Toyota. In 1902, Sakichi Toyoda invented an error proof wooden loom machine that changed production forever. This invention introduced a new key mechanism (Jidoka), which stopped the machine whenever a thread broke, thereby preventing errors and defects. This became the Jidoka concept of Toyota Production System (TPS) which is closely connected to Muda elimination. Kiichiro Toyoda (who became the director of Toyoda Automatic Loom Works in 1921) always encouraged staff to make suggestions and not to be afraid to make mistakes. Furthermore, he expressed the importance of learning from failure and making small improvements each time. Kaizen is a philosophy that involves all employees and defines management's role in continuously encouraging the implementation of small adjustments that make the process more efficient, effective, manageable, and adaptable. These are usually accomplished at little or no extra cost, without sophisticated techniques or expensive equipment.

Kaizen focuses on simplification by breaking down complex processes into their sub-processes and then improving them. Usually, Kaizen starts with how to produce efficiently with limited resources (man, material, machine). This means that it is not necessary to utilize all the available resources and manpower. On the contrary, it should be a focus on savings in manpower, space, equipment, material, and time and an elimination of unnecessary processes, even signatures for paperwork. For example, if something is found to be unused, it is better not to try to use it, but to remove it at once. If some employees are underutilized, they can be asked to help with Kaizen. Savings as a result of Kaizen can usually be achieved by asking how much manpower and how many goods are needed to achieve a target productivity level. Figure 1 illustrates the meaning of Kaizen as a simple example of saving time and effort.

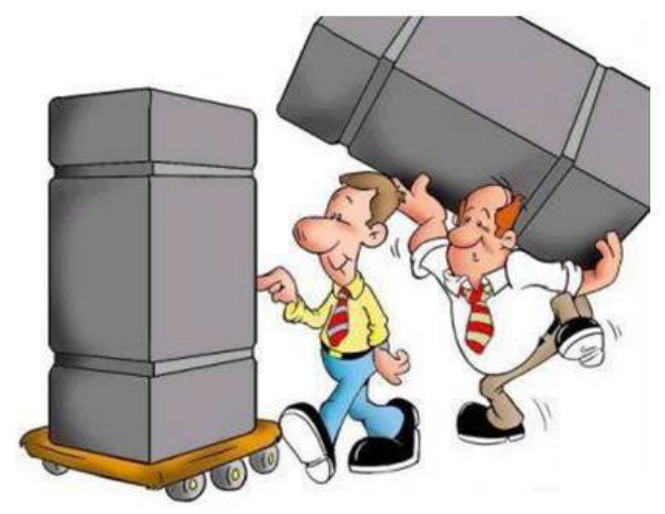

Figure 1: Thinking of Kaizen.
Kaizen specialists should have some capabilities that make their characters and skills different from any normal technician or employee. Hence, Kaizen specialists should have the ability to perform advanced tasks, to complete them faster and to deal with earlier processes, such as reception, estimates, parts ordering, and dealing with customers.

Taiichi Ohno identified an important aspect of the Kaizen Spirit when he said, "Despite knowing the outcome if I do it this way, I am compelled to do otherwise" $[7,16,17]$. Kaizen culture refers to the ability to step back from all activities, observe current processes and to propose solutions to problems. Kaizen spirit refers to an innate sense of continuous improvement in daily life in any place (in the workplace and even at home) and a continuous drive to improve.

Kaizen is the DNA of Toyota, which is improving business operations continuously and always driving for innovation and evolution. Kaizen is an important pillar of The Toyota way (the learning organization/education and training), which is based on two important pillars or key factors of The Toyota Way as follows:

Continuous improvement: Continuous Improvement contains

Challenge: It means forming a long-term vision, and meeting challenges with courage and creativity to realize dreams.

Kaizen: It means continuously improving business operations, and always driving for innovation and evolution.

Genchi Genbutsu: It means going to the source to find the facts in order to make correct decisions, build consensus and achieve goals quickly and efficiently.

\section{Respect for people: Respect for People contains}

Respect: It means respecting others (including all shareholders and colleagues) by making every effort to understand each other, taking responsibility and doing the best to build mutual trust, mutual responsibility, and sincere, effective, communication.

Teamwork: It refers to stimulating personal and professional growth, sharing the opportunities of development and maximizing individual and team performance. It includes commitment to education and personal development, respect for the individual, and realizing consolidated power as a team.

The Toyota Way has been successfully applied in many dealerships and in many companies other than Toyota. The results and benefits of applying The Toyota Way are summarized as follows:

For the customer: Cost reduction through reducing waste and whilst providing better vehicle quality and competitive pricing for customers.

For the dealer: Improving production and efficiency through Kaizen implementation in daily operations. Empowering employees who can identify problems and applying Kaizen actions immediately.

Kaizen is the Toyota Philosophy that is the foundation of any business management or system for any company. The objectives of Kaizen and the Kaizen Division are summarized as follows:

- Continuous improvement for the organization.

- Cost reduction and cost optimization in order to save manpower, space, equipment, material.

- Continuous training and education for the employees of the organization and their involvement in Kaizen activities. 
- Increased productivity of the employees in the organization.

- House of Genba Management as will be explained in a later section [1-20].

\section{Kaizen Tools and implementation}

Kaizen improvement and implementation is based on the use of the following important principles and tools:

1. Observing all working process then differentiating and sorting the value added and non-value added work activities.

2. Applying the principles of motion study. It will be achieved by using the pull production system not the push system (as will be explained in later section).

3. Applying the principles of material handling and use of onepiece flow. It will be achieved by using the pull production system not the push system (as will be explained in later section).

4. Documentation of Standard Operating Procedures (SOP).

5. The 5S principle for workplace organization which is a philosophy of good housekeeping. It is a practical concept that means to realize the smoothest flow and a synchronization in processes. $5 \mathrm{~S}$ is the key point in the workplace to help accomplish work quickly, correctly and safely. The five S's are explained in Table 1 [21-27].

6. Visual management by means of visual displays that everyone in the organization can use and check for better communications.

7. Genchi Genbutsu and management from the source (Genba): Genchi Genbutsu (local goods) is a key factor of The Toyota Way. The first 2 Kanji, local (Inch in hiragana), mean the source while the second two Kanji, Actual thing (Animal in Hiragana), mean actual products. Hence, Genchi Genbutsu means going to the source place to observe and find facts, determining what is really going on, and making correct decisions. Because at the genba (source) there is evidence (images, atmosphere, and hidden facts) that cannot be extracted from data alone, Mr. Toyoda maintained that it is better to ask the product, not the people. As a result, it is possible to gather the facts, quickly build consensus, implement a decision and achieve timely improvements. In summary, Genchi Genbutsu can be best described by "seeing is better than hearing".

The 5 Genchi Genbutsu and Genba principles are summarized as follows:
- When an abnormal case occurs, go to Genba first.

- Check with Gembatsu (machine, material, failures, rejects, unsafe conditions etc.).

- Take temporary countermeasures on the spot.

- Remove root causes.

- Standardize to prevent trouble.

Genchi Genbutsu is the first step to rejuvenate TOYOTA and is applied throughout the company. Some important words on Genchi Genbutsu published in The Toyota Way 2001 can help to understand this principle as follows:

A full understanding of situations and problems requires extensive study and the gathering of all relevant quantitative and qualitative facts. Taiichi Ohno stressed the importance of collecting 'facts from the source' while Kiichiro Toyoda identified 'hands-on experience' as vital $[1,7,28]$.

8. Toyota Production System (TPS) including the elimination of Muda: This will be explained in details in a later section with a case study [29-38].

9. Poka-yoke to prevent or detect errors (Rework). The essence of poka-yoke is to design the process so that mistakes are either impossible, or are easily detected and corrected.

10. Hoshin Kanri (Policy Management): the first Kanji, Person, that is $\mathrm{HO}$ in Romaji means direction; the second Kanji, needle, that is SHIN in Romaji means focus or needle, the third Kanji, tube, that is KAN in Romaji means control while the last kanji, Management, that is RI in Romaji means logic. Hence, Hoshin Kanri is the managing and steering of any organization in a clear direction. Hoshin Kanri is an action to establish a framework in order to maximize output.

11. Do it the right way principle: (Fix-it Right, Fix-it Fast and Fix-it Once). In other words, no incomplete or defective job should be passed and responsibility should be taken to ensure this. Katsutada Masumoto regarded 'Fix-it Right the first time' as the root of all Toyota service activities.

12. When facing a problem or even a mistake, there is a principle to grasp problems, analyze the root causes, and then follow the problem solving process. Therefore, in order to prevent problems, the following steps should be considered:

\begin{tabular}{|l|l|l|}
\hline Japanese & Alphabetical & English \\
\hline sort out & Seiri & Sort, separate, sift, and remove: Decide or separate what is needed (items) \\
\hline Roasted rice & And what is not, and dispose of all items that are not necessary. \\
\hline Rectify & Seiton & Set in order, straighten, and configure: Arrange the stored items/ provide \\
\hline Cocoon & & orderly storage in the right place for all necessary items to be easily found \\
\hline And used when needed. \\
\hline clear & Seiso & Sweep, shine, wash, clean and check: Maintain a clean worksite at all times \\
\hline Tough & & In order to make work easier, safer, healthier and more satisfying. Do not \\
\hline clean & Seiketsu & Keep equipment and areas spick and span: Clean tools and ensure that work \\
\hline Long time no see & & can be easily and safely conducted and there are no obstructions \\
\hline Discipline & Shitsuke & Sustain self-discipline, custom and practices: Maintain initiative to put 5S \\
\hline Shoes & & Into continuous common practice. \\
\hline
\end{tabular}


- Be sure to follow the standard operation and instruction (work procedure and work sequence).

- Carry out the work correctly and completely.

- Do a perfect job.

- Concentrate on the work

- Make sure to 'STOP' 'CALL' and 'WAIT' in case of an emergency.

The problem analysis and problem solving process can be summarized as follows:

Most firms actively engaged in continuous improvement train their work teams to use the plan do check act cycle for problem solving. Another name for this approach is the Deming Wheel, which lies at the heart of the continuous improvement philosophy. The cycle comprises the following steps:

Plan: The team selects a process (activity, method, machine, or policy, for example) that needs improvement. The team then documents the selected process usually by analyzing data, setting qualitative goals for improvement, and discussing various ways to achieve the goals. After assessing the benefits and costs of the alternatives, the team develops a plan with quantifiable measures for improvement.

Do: The team implements the plan and monitors progress. Data is collected continuously to measure the improvements in the process. Any changes in the process are documented, and further revisions are made as needed.

Check: The team analyzes the data collected during the 'Do' step to find how closely they correspond to the goals set forth in the 'Plan' step. If major shortcomings exist, team may have to reevaluate the plan or stop the project.

Act: If the results are successful, the team documents the revised process so that it becomes the standard procedure for all who may use it. The team may then instruct other employees in the use of the revised process.

Problem solving projects often focus on those aspects of operations that do not add value to the product or service. Value is added during operations, such as machining a part or serving a customer. No value is added in activities such as inspecting parts for quality defects or routing requests for loan approvals to several different departments. The idea of continuous improvement is that activities which do not add value are wasteful and should be reduced or eliminated.

Some words on Genchi Genbutsu published in The Toyota Way 2001 on identifying problems and analyzing root causes can be elucidated as follows:

Problems arising from variances between goals and current situations are explored until their root causes are found by means of first-hand investigation. Studies are commended early; the widest range of options is considered in designing countermeasures. Taiichi Ohno's approach is to observe the production floor without preconceptions and with a blank mind, thinking 'why' five times to every problem, especially where the root cause lies hidden beyond the source. Sakichi Toyoda reinforces this with the belief that "There is no fixed model for making decisions. The key is to study the problem thoroughly and to decide on what is believed best" $[1,7,28]$.

13. Toyota Business Practices (TBP). It is an action to practice The
Toyota Way then to realize continuous achievements efficiently for all positions or functions and to enhance quality in order to make company growth in the mid to long term. TBP consists of eight steps of concrete actions and processes summarized as follows:

$>$ Clarifying the problem.

$>$ Breaking the problem down.

$>$ Setting a target.

$>$ Analyzing the root cause.

$>$ Developing countermeasures.

$>$ Seeing countermeasures through.

Evaluating and monitoring both results and processes.

$>$ Standardizing successful processes.

and these actions above can be driven and achieved by dedication to the following principles:

$>$ Customer first.

$>$ Always confirming the purpose of the work.

$>$ Ownership and responsibility.

$>$ Visualization.

$>$ Judgment based on facts.

$>$ Thinking and acting persistently.

$>$ Speedy action in a timely manner.

> Following each process with sincerity and commitment.

$>$ Thorough communication.

$>$ Involvement of all stakeholders.

14. Team dynamics, which include problem solving, communication skills, and conflict resolution. Kaizen relies heavily on a culture that encourages suggestions by operators who continually try to incrementally improve their job or process.

15. The Kaizen Idea Bank and Kaizen Marathon Projects. "Thinking outside the box" can help in brainstorming new ideas. In general people have a lot of ideas. The key point is to encourage employees to believe that submitting their ideas can make a difference, 'Making tomorrow better than today' [ALJ Slogan]. Toyota Motor Corporation (TMC) successfully involves all staff from top to bottom in the Kaizen process, and as a result they give incredible ideas. Such a process also strengthens the employee commitment and sense of belonging to the company, which is crucial for increasing their motivation. The TOYOTA Creative Suggestion System produces about 1,000,000 ideas per year with a principle of 'Good Thinking, Good Products'. Other companies, such as Dell Computer Company, have fully adopted a similar approach. As Taiichi Ohno pointed out, "Once you discover the bountiful results of Kaizen improvement, you will never forget the spirit of Kaizen" $[1,7,28]$. Therefore, Kaizen has become an important business culture.

16. Cooperation between and within company departments and 
effective consensus building. This could be achieved by sharing of goals and quantitative objectives, and any variances between goals and performance should be explained thoroughly to avoid misunderstandings. As goals are established through consensus building, the processes to be adopted to reach them are defined as well through the Hoshin Kanri process. In this case, Toyota's main principle is to seek full consensus with members of all groups, including those from other Toyota organizations. This is in preparation for practical, effective and smooth implementation of solutions without obstacles or conflict. Mr. Eiji Toyoda said that "Whenever you decide to start something new or modify an existing process, coordination among many divisions and departments always becomes necessary. I want you to think for the entire company rather than yourself alone, coordinate with other divisions, and lead on, no matter what, to concrete results" $[1,7,28]$.

Figure 2 summarizes the above tools and shows the frame of seven pillars of success for any company in applying Kaizen.

\section{Toyota Production System (TPS)}

Introduction: When the Pacific War ended, Japan was in ruins and a super belt-tightening policy called 'Dodge's Line' was implemented to reconstruct public finance. Toyota resumed production in 1950 but ran into financial difficulty and could not obtain any support from the bank or the steel companies. It was forced to separate the production and sales areas into different companies, 2000 staff were laid off, and President Kiichiro Toyoda resigned. This resulted in Toyoda's philosophy that the company should build up a management culture that would never have to rely on the support of banks again (business without loans). This experience became the background to the establishment of the Toyota Production System [1-3,6,7,16].

\section{TPS requirements before starting TPS in business:}

The following requirements or rules in business should be considered before starting or at the beginning of TPS:

- Do not buy or transport things (materials), which are not needed immediately.

- Do not make or transport things that cannot be sold immediately.

- Exchange produced goods/ products for money as soon as possible.

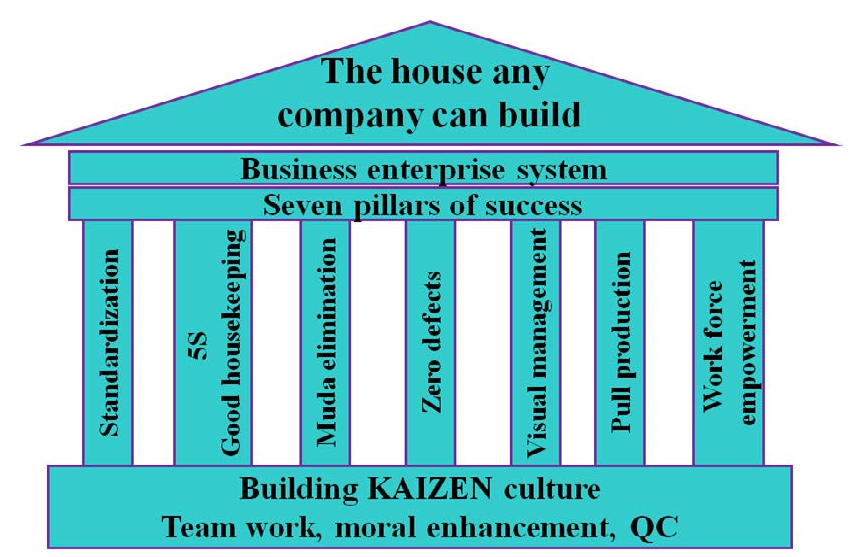

Figure 2: Kaizen tools and the seven pillars of success.
- Do not make or pass on any defective products or goods.

To produce vehicles that could compete with the prices of other companies, such as GM and Ford, Toyota came up with business ideas (principles) and a production system unique to Japan. These principles are Jidoka and Just-In-Time which were ideas developed by Sakichi Kiichiro [1-3,6,7,16].

TPS principle of generate more profits: The traditional way of increasing and generating more profits depends on the sales price, which is equal to the sum of the cost plus the profit.

\section{Price $=$ Cost + Profit}

Hence, the traditional formula to increase and generate more profits is to increase the selling price. This traditional way considers that the cost is equal to the actual cost. Figure 3 shows the traditional way of generating more profits.

The TPS formula considers that the cost is equal to the actual cost plus the waste. Hence, the profit is equal to the sales price minus the cost.

Cost $=$ Actual Cost + Waste. Profit $=$ Sales Price-Cost.

In order to increase the profit, the key point is reducing the cost because the selling price is decided by the market. The best way to do this is by elimination of Muda. Figure 4 illustrates the TPS way of generating more profits.

The Toyota Production System (TPS) is a part of Toyota business philosophy, which is a lean production system. The basis of the Toyota Production System is production, transportation improvement and control enhancement. There are three types of productivity. They are equipment productivity, material productivity and labor productivity. Equipment productivity and material productivity can be easily copied by using the same equipment or materials that are usually used in the market or benchmarked. Other competitors can easily copy these, but not labor productivity. Therefore, in order to be competitive it is important to increase labor productivity to widen the cost gap between companies. Labor productivity improvements are not merely improvements where people are just asked to 'Do it quickly' or 'Run

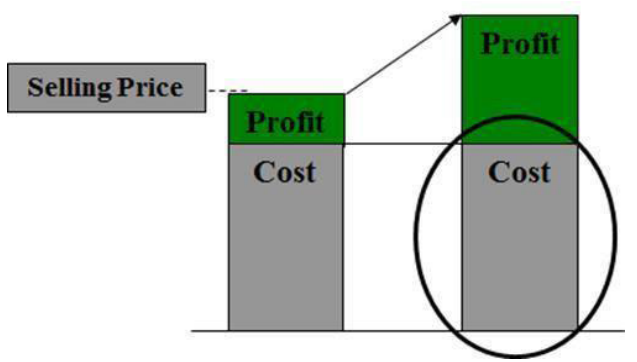

Figure 3: The traditional way of generating more profits

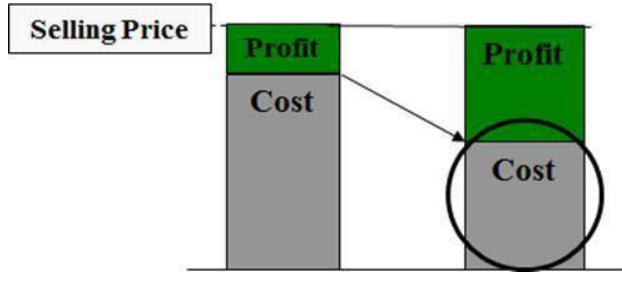

Figure 4: The TPS way of generating more profits. 
and get it done' (Intensification of Labor). Productivity improvement based on TPS and Kaizen activities are about changing wasteful movement (movement Muda) into work that adds value. In order to produce world-class quality automobiles at competitive price levels, Toyota has developed an integrated approach to production which manages equipment, materials, and people in the most efficient manner while ensuring a healthy and safe work environment. When TPS is put into practice, manpower reduction (labor saving) can be attained. It is about meeting the production target with as small a number of workers, equipment and energy as possible. This means improving work procedures, machinery and equipment to free workers from particular jobs on a production line consisting of one or more workers. It is important to develop a flexible use of manpower rather than simply reducing the numbers as there may be fluctuations in supply and demand which need to be met. However, to achieve this flexibility, several issues should be considered. Firstly, the scale and the volume of production should be identified, then the employees should be allocated to the various areas of the production line without interference in motion. The number of workers in the production line can be adjusted to match the demand. If there is high demand, additional workers join the line and production goes up, but if there is low demand the number of workers is reduced. Secondly, when the number of workers is reduced in response to demand fluctuation, the workload must be evenly allocated to the remaining workers. This requires process division, promotion of multi-skilled workers, and preparation of all-purpose equipment. Finally, the work progress needs to be carefully monitored for delays and any spare capacity identified. Such an action is important, because any possible reduction (or increase) in the number of workers can be quickly implemented [1-3,6,7,16,29-31].

The pillars of Toyota production system: The Toyota Production System is built on two main principles (that are the main pillars of TPS) which are Just in Time (JIT) and Irregularity Control (Judoka). Underlying this management philosophy, the entire Toyota production process depends on the concept that 'good thinking means good product'. In addition to the previously mentioned main pillars of TPS, elimination of Muda and using the Standardized Operation Procedures (SOP) are very important factors in TPS as shown in Figure 5 [1-12].

Just In Time (JIT): Just-In-Time means collecting, producing and transporting only the necessary items (for customers, for work) at the required time in the correct quantities (from the previous process). Unnecessary items or inventory should not be held. JIT aims at achieving a short and stable lead-time. In order to understand and apply Just-In-Time (JIT), it is very important to explain the following principles or concepts: Heijunka, Takt Time, Lead-Time, Continuous Flow Processing and the Pull System.

\section{Standardized Operation Procedure}

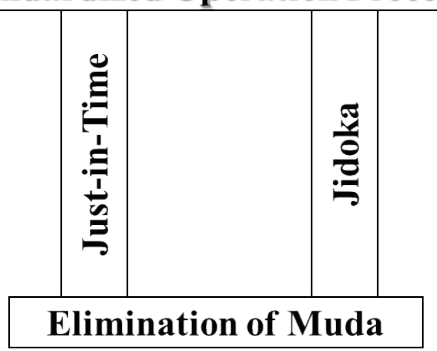

Figure 5: The Two Pillars of TPS.
The first step to realizing JIT is to adopt the Pull System and Continuous Flow Processing, and then to set Takt time. The second step is to standardize work based on Takt Time [1-9,36-40].

Heijunka: Heijunka is an essential precondition of Just-In-Time (JIT) which is a situation where the type and quantity are averaged out evenly over time (manufacturing sequence when there are many types) as shown in Figure 6. Heijunka is a situation where the type and quantity should be at the same level and averaged out evenly over time, so that the lead-time and fluctuations in inventory and space can be reduced, allowing more efficient production.

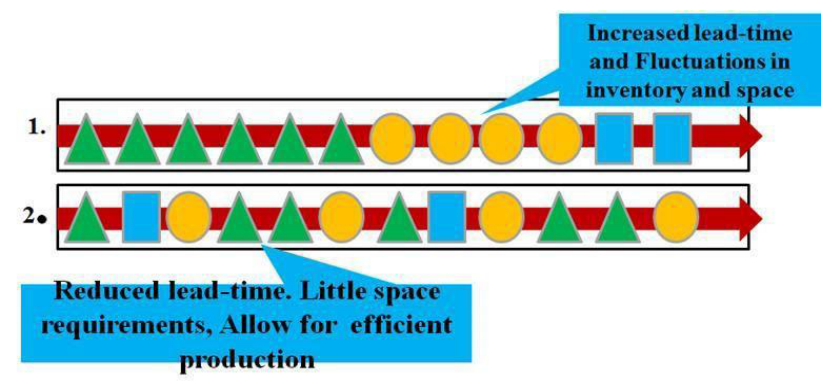

Figure 6: Heijunka as a precondition of Just-In-Time (JIT).

Takt time: Takt time is the standard time for production to match the speed of sales. It is the time required to produce one product or part or vehicle (Necessary production/Sales speed). In general, Takt time is a value derived from dividing regular daily work time by daily requirements.

Takt Time=Operation time for 1 day (minutes)/Necessary production quantity for 1 day

Lead time: Lead-time is the period of time taken from obtaining materials to converting them into capital. Therefore, lead-time reduction has a beneficial effect on the improvement of capital turnover, and increases in the ability to deal with market change and fluctuations can lead to a great increase in competitive strength. When calculating lead-time, the processing time and non-processing time should be considered.

Lead time reduction: The lead-time consists of processing time and stagnation time. Therefore, the first step in lead-time reduction is eradication of stagnation time. Since stagnation causes various problems, eradication of the time is very important. If stagnation occurs or becomes longer, the following results of stagnation will be clear: if the amount of stored goods increases, there will be a corresponding need for more storage space (or parking lots), and a storage manager will be required. As a result, the time spent to locate the necessary goods will be longer. Furthermore, a long stagnation time will increase the possibility of the quality of the goods deteriorating or being damaged. Moreover, it can affect the liquidity of capital.

As the Lead-time=Processing time + Non-processing (stagnation) time, the effects of lead-time reduction are as follows:

- Improved capital turnover.

- Increased ability to deal with market change/fluctuations (volume, types).

- Increased competitive strength.

This is an important part of the Kaizen sequence. 
Continuous flow processing and lead time reduction: Continuous flow processing means to make or to carry out production of one item (one-piece) or product at a time without stagnation of goods between processes. The JIT principle depends on continuous flow processing and lead-time reduction. To calculate lead-time, the cycle time is multiplied by the standard in-process stock, where the standard inprocess stock means the minimum required for the operation to proceed in a repeated sequence.

Lead-time $=$ cycle time $\times$ standard in-process stock.

Reducing the lead-time could be achieved by shortening the cycle time of the manpower, time/vehicle and/or reducing standard inprocess stock. Figure 7 illustrates the shortening of the flow where the number of processes each worker carries out at each stage is reduced. The upper row of the Figure 6 units of standard in-process stock. When the worker's cycle time takes 20 minutes for example, the lead-time takes 120 minutes. The mid row of the Figure 3 units of standard inprocess stock with lead time of 60 minutes. The third row shows one unit of standard in process stock for 20-minute lead-time. As shown here, when reducing the standard in-process stock with maintaining the same worker's cycle time (productivity remaining the same), the lead-time will be drastically reduced. Furthermore, if job improvement reduces the worker's cycle time, the lead-time will be further reduced. Continuous flow processing aims to erase any stagnation between processes and to initiate one piece at a time production. The aims of flow processing are to establish one-piece at a time production, a smooth flow of goods and equipment, multi-process handling, multiskilled employees, and a good arrangement of the process order. The advantages of shortening the flow are that: it improves quality, shortens lead-time, realizes prompt delivery, reduces inventory and stagnation, uses minimum resources, simplifies management (less managerial and administrative intervention), and realizes minimum cost and maximum profit.

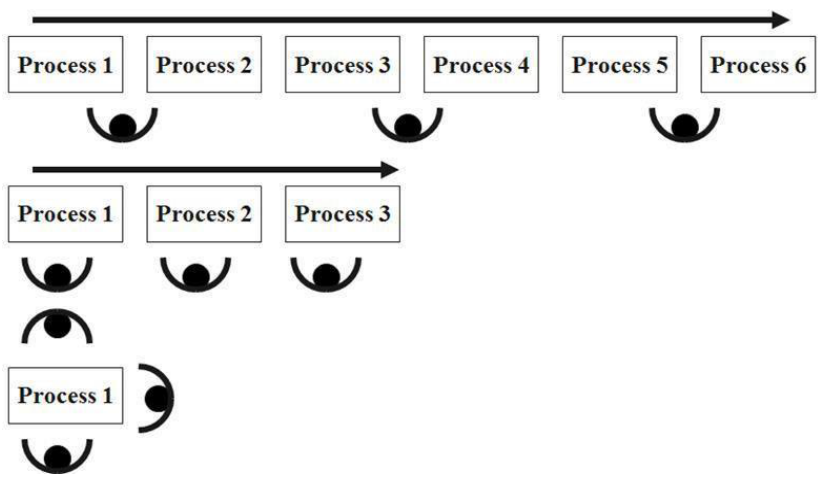

Figure 7: A sample of shortening the flow.

The purpose of continuous flow processing is to shorten lead-time thereby improving productivity.

Here the role of Kaizen appears clearly.

\section{Conditions for minimizing the flow}

1. Standardization

2. Applying $5 \mathrm{~S}$

3. Visual management

4. Muda management

\section{Reorganizing management structure}

6. Building KAIZEN culture.

Pull system: To sell one item or product and then make another. A following process takes (pulls) only the exact number of items required at the necessary time from the previous process. Hence, it is important to determine sales conditions before production. To smoothly conduct a pull system, avoiding stagnation between processes and guaranteeing one-piece flow, the Kanban System is adopted which is to produce and transport only what is sold.

Irregularity control (Jidoka self-determination): Irregularity Control (Jidoka) is the stopping of a production line either automatically or by an employee in case of irregularity, such as an equipment malfunction, a quality problem or work being late. This aims to prevent passing or producing any defective goods or products by stopping the line if there is any irregularity. Hence, only non-defective products are forwarded to the next process. Therefore, quality control must be built into each process, so that there is no need to assign staff merely to watch machines. This creates manpower savings and enhances one great Toyota principle which is, 'Do not treat people as machine monitors'. Jidoka could mean investing in machines with humanlike intelligence which identify where the irregularity occurs. An example of this is the Andon system, which is an electric bulletin board that shows at a glance where the irregularity took place so that the employees concerned can take immediate action. In summary, Jidoka (irregularity control) involves stopping the process when there is an irregularity and making the irregularity clearly visible. In other words, Jidoka is visual control. To find and visualize irregularities (make them obvious), it is necessary to set standards (rules) for determining what is regular or irregular, including the standard time, process flow, and/ or standard of work. To control irregularities proficiently, it is necessary to have 'the conviction that rule infractions are never overlooked'. This is an indicator of good management and Kaizen action. When an irregularity occurs, it is important to assign who will take what action, and investigate and analyze the root cause by following the four basic steps of Jidoka which are: Occurrence (Why did irregularity occur?); Stop (Why did the line fail to stop upon the moment of irregularity?); Resume (Why was it passed on to the next process?); and Outflow (Why did it take so long to resume?). Following that, these irregularities should be resolved. Troubleshooting is required and corrections made to prevent recurrence and ensure the continuance of Kaizen.

\section{Jidoka has the following significant benefits and advantages:}

1. The passing of defective products is prevented.

2. Equipment breakdown is prevented.

3. The efficiency of management is improved by monitoring irregularities. Hence, the meaning of management is altered. Since the defects are stopped automatically, full-time inspectors become unnecessary. As a result, extra staff used to watch machines can be used in other more productive areas (manpower savings)

4. Production can continue without any drop in productivity.

5. Problems become clearly identifiable so that Kaizen can be accomplished. The recurrence of malfunctions can be easily prevented contributing directly to stable equipment operation and consistent quality.

Elimination of Muda: The first step is to identify that waste exists and where it occurs in the workplace, categorize and name it, and 
develop motivation to remove it. Furthermore, the difference between what is good and what is waste (or Muda) should be clear.

The 7 Muda are seven classes of waste as follows:

1. Overproduction: Production of unnecessary items results in unsold stock. Overproduction leads to other Muda, such as the need for a place to store goods, the need for managers or controllers to oversee the stock, and the need to maintain it in the right environment to avoid deterioration or loss of quality.

2. Waiting and delay: Any waste of time leads to a loss in profit.

3. Transportation: long transportation means extra cost and time.

4. Production of goods to a higher quality than needed: Additional costs and time will be incurred for items that cannot be sold.

5. Extra inventory or stock (un-recovered funds): This needs a storage area and equipment, management and maintenance to prevent deterioration, and ties up much needed capital.

6. Wasted motion: Locating parts from different areas or transferring work from one area to another for no valid reason wastes valuable time.

7. Defective parts repair/reject/rework: Rectifying defects or making repairs after the fact leads to extra cost.

TPS aims to eliminate Muda (waste) occurrence in the processes. Figure 8 shows an example of eliminating Muda from a process.

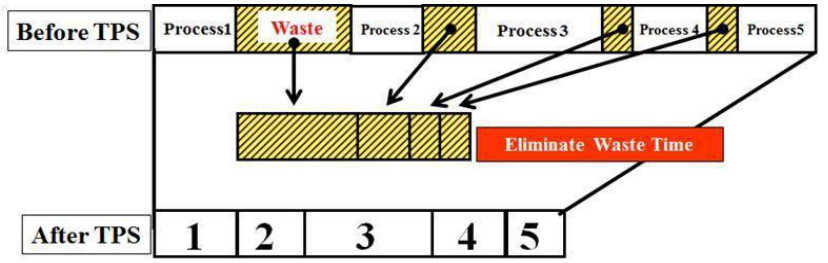

Figure 8: An example of eliminating Muda from process.

Work efficiency and job procedures can be improved by going to Genba, the actual workshop, and employing Genchi Genbutsu principles. Through observation, the worker's movement (eyes, hands, and feet or legs) can be evaluated and the following questions asked:

1. Does the worker have to stretch or move far to complete any job?

2. Does the worker have to wait between jobs?

3. Can the worker move smoothly between one job and the next?

If any Muda is discovered through observation and evaluation, improvements should be made. Figure 9 explains and summarizes in detail the pillars and supports of TPS, including the points of each pillar.

\section{Business requirements before starting TPS}

- 'Business without loans' means not buying or transporting materials or goods which are not immediately necessary. Goods should be exchanged for money as soon as possible.

- Defective goods should never be made nor passed on.

- Muda (waste) occurrence in the processes must be eliminated.

- Work done by people and machine should be clearly separated.

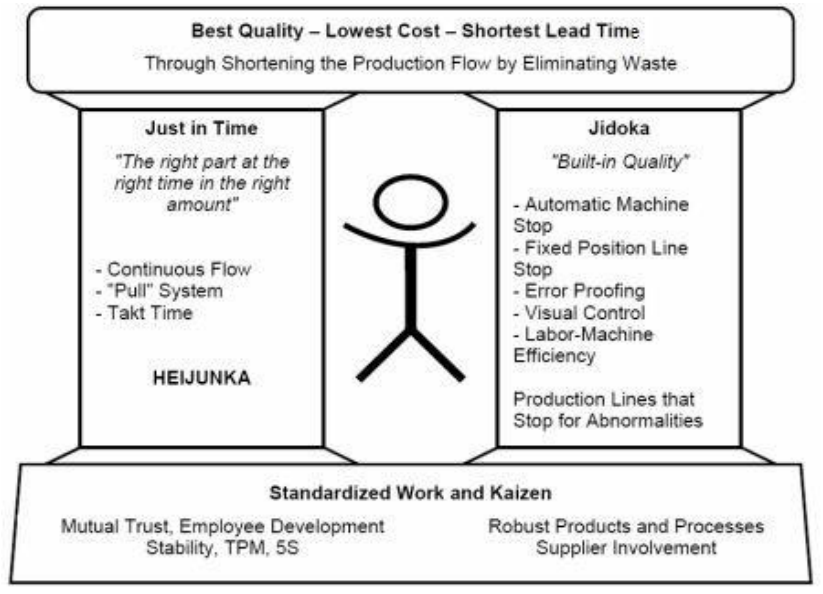

Figure 9: A Summary of the two pillars and supports of TPS.

- Employee's value-added productivity should be improved.

\section{Key factors for successful Kaizen}

The following factors are important for successful Kaizen:

1. Management support and involvement.

2. Commitment from management, associates and employees.

3. Team dynamics, which include problem-solving, good presentation and communication skills, and the ability to resolve differences.

4. Kaizen depends largely on a culture that encourages suggestions from workers and employees to continually develop business or production processes.

5. Kaizen should be part of the daily work.

6. Utilization of Kaizen tools (5s, TPS, etc...).

7. Recognition for the importance of Kaizen projects and activities.

\section{Kaizen implementation}

In order to implement Kaizen, the following important points should be considered:

1. The current situation should be accurately described and the problem clearly identified.

2. The gap between the current situation and the target should be analyzed.

3. The Kaizen target and positive points should be set.

4. The type of improvement should be determined, including TPS implementation if applicable and Kaizen tool.

5. The expected results when applying the Kaizen should be determined.

6. Kaizen should be implemented.

7. The full impact (including financial) should be identified.

8. Kaizen implementation must be evaluated, and future plans decided. 


\section{The Case Study: Implementing Kaizen Principles at Port Installed Options Center (PIOC) in Toyota Saudi Arabia}

The following section presents the results of a case study into the implementation of the Kaizen principles at the Port Installed Option Center (PIOC) at Toyota, Saudi Arabia. This case study was selected to elucidate the benefits of Kaizen to business excellence by presenting the results of implementing the Kaizen principles at the Port Installed Options Center at Toyota, Saudi Arabia. The use of relevant Kaizen tools, including the Toyota Production System (TPS), 5S and the seven Muda, enabled understanding of the system and identification of critical problem areas. The Kaizen target was set after analyzing the problems and identifying the gap between the existing system and the TPS (new system). PIOC consists of 4 plants including the National Distribution Centre (NDC). All of them are located near the port of Jeddah on the Red Sea. These plants are part of Toyota, Saudi Arabia, which is itself a part of Abdul Latif Jameel Co. Ltd. (ALJ). The PIOC mission is to accessorize new vehicles to a high quality at optimum cost in minimum time, using The Toyota Way in production. The PIOC vision is to become a leading vehicle accessorization production line in the Toyota Network, using TPS and The Toyota Way to satisfy market needs and achieve business excellence. PIOC brings imported Toyota vehicles from Jeddah port to PIOC plants, and then installs the necessary accessories to vehicles according to the agreements with TMC. Finally, the prepared vehicles are delivered to the customers in any city in the Kingdom of Saudi Arabia (KSA). These vehicles are referred to as the accessorization production or accessorized vehicle volume whereas the Total Vehicle Sales Volume includes those vehicles that do not need any accessories. Table 2 shows the PIOC plant profile. Figure 10 illustrates (PIOC) accessorized vehicles and sales volume per year.

\section{The old stall-type production}

The accessorized volume was produced in PIOC using an old stalltype production method which is a push system that was employed in the period 1990-2007. A vehicle was parked in a stall (place or working area) and one or more workers installed all accessory items in it. The installer had to collect the parts from the warehouse and assemble them in the accessorization area. In order to avoid repeated trips, installers often brought extra parts in advance for the next few days. This often resulted in damaged parts. Furthermore, these extra parts took up valuable space in the accessorization area. The facilities of each stall were neither designed nor suitable for an annual production of more than 180,000 meaning that the figure of 212,400 vehicles for 2008 could not be met. As a result, it was necessary to build new facilities or plants (factories) in order to achieve this. Figure 11 illustrates stall-type production in plants 1, 2 and 3 .

The main disadvantages and problems of the stall-type production method before applying Kaizen can be summarized as follows:

- A low production rate of not more than 188,000 vehicles per year (50 vehicles per installer monthly).

- Poor space utilization of not more than 63 vehicles per stall monthly. Moreover, parts occupied valuable space in the accessorization area. These parts impeded the movement of both vehicles and installers and often resulted in damage to the parts or vehicles.

- A low Associates Engagement Index (Q12) of 2.91 in 2007 measured by Gallup Co. as an indicator of team work and the relationship between employees.

- Difficulty in controlling manpower movement.

- Production based on individual motivation (man of the month) not team work. Poor teamwork, communication and relationships.

- A large discrepancy in incentives for installers (from US \$ 100 to $\$ 1,500$ per month).

- Muda causing time lost for installers, arranging tools, vehicles

\begin{tabular}{|c|c|c|c|c|}
\hline & Plant 1 & Plant 2 & Plant 3 and 4 & Total \\
\hline Plant area & $2208 \mathrm{~m}^{2}$ & $1552 \mathrm{~m}^{2}$ & $3670 \mathrm{~m}^{2}$ & $7430 \mathrm{~m}^{2}$ \\
\hline Operation started & 2001 & 1992 & 2003 & \\
\hline Number of employees & 160 & 95 & 122 & 377 \\
\hline Average monthly production & 10,000 & 3,000 & 4,000 & 17,000 \\
\hline Models accessorized & $\begin{array}{c}\text { Avalon, Aurion, Camry, Corolla, } \\
\text { Yaris, Rav4, Hiace, Dayna, } \\
\text { Coaster, Terios, Sirion, Materia, } \\
\text { Lexus }\end{array}$ & Hilux & $\begin{array}{c}\text { L/Cruiser Wagon, L/Cruiser } \\
\text { Pickup, Prado, Fortuner, Innova, } \\
\text { FJ Cruiser, Seqouia }\end{array}$ & \\
\hline
\end{tabular}

Table 2: PIOC Plant profile.

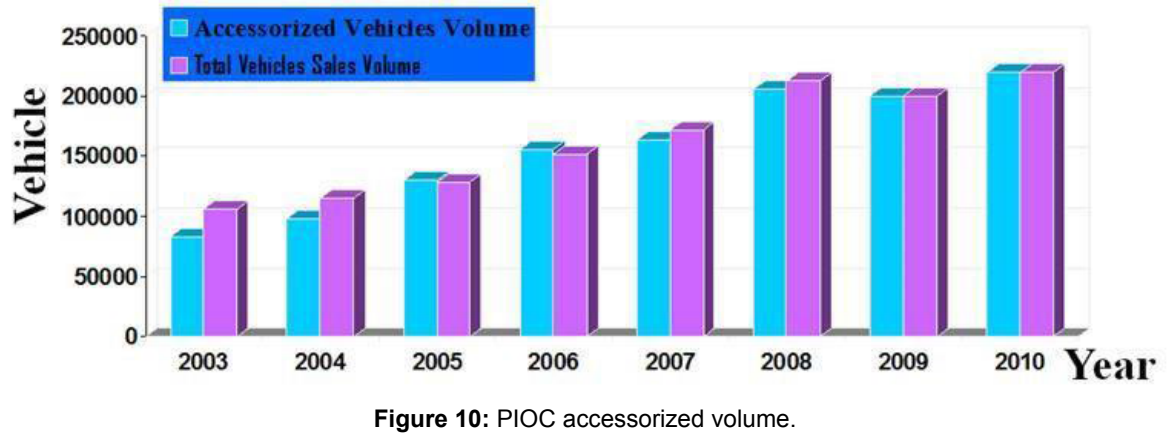




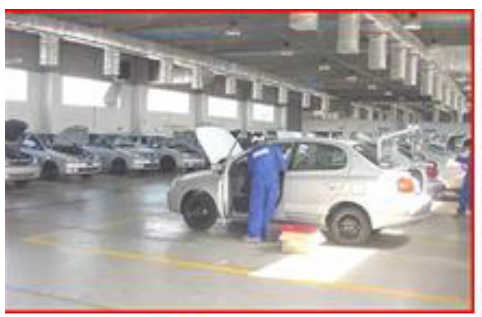

Plant 1

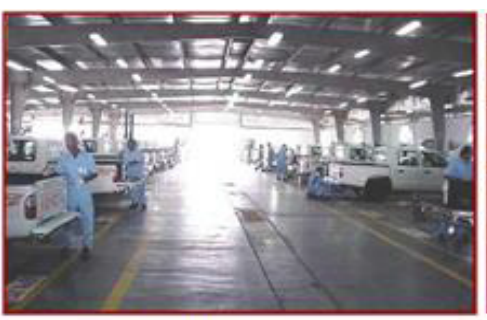

Plant 2: Hilux

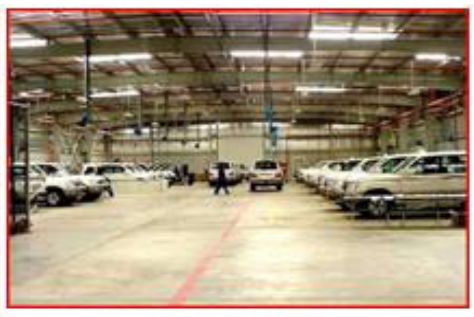

Plant 3: Land Cruiser

Figure 11: Samples of stall-type production.

\begin{tabular}{|c|c|c|c|c|c|c|}
\hline \multicolumn{7}{|c|}{2006 Business Plan } \\
\hline Yearly plan & 2005 & 2006 & 2007 & 2008 & 2009 & 2010 \\
\hline Vehicle sales (units) & 129,000 & 159,720 & 188,000 & 212,400 & 233,500 & 257,700 \\
\hline Required installers & 215 & 266 & 312 & 349 & 389 & 429 \\
\hline Required stalls & 171 & 212 & 249 & 281 & 309 & 340 \\
\hline Actual installers & 215 & 266 & 312 & Became (275) as per TPS result & & \\
\hline No. of vehicle damages & 366 & 445 & 480 & 115 & 139 & 164 \\
\hline Percentage of vehicle damages & 0.284 & 0.279 & 0.255 & 0.054 & 0.059 & 0.064 \\
\hline
\end{tabular}

Table 3: $(\mathrm{PIOC})$ Business plan and required installers and stalls.

and collecting parts from warehouse. Weak and poor planning for both part preparation and vehicle movement.

- Low quality resulting from difficulties in final quality inspection, and lack of quality control during the process.

- A high number of vehicles damaged due to poor layout and flow (480 vehicles in 2007). This number was estimated to be about $30 \%$ of the total vehicles.

\section{Problem description}

In 2007 , the vehicle sale was 188,000 units and 312 workers were required to achieve this. The target was set for 212,400 vehicles in 2008 , which required 349 installers. The increase in sales volume required directly increasing the production capacity, facilities and number of installers. However, the increase could not be met because of the design and setup of the stalls. Table 3 shows PIOC business plan including required installers and stalls.

\section{Gap analysis}

As per 2007 business plan, US $\$ 4,000,000$ was budgeted to establish additional facilities and recruit about 37 installers to be able to reach the target of 212,400 sales in 2008 using stall-type production.

\section{Kaizen target}

The Kaizen target was to implement TPS in order to meet the sales target of 212,400 for 2008 without having to build any additional facilities or recruit additional manpower. In order to achieve this target, the following objectives were set:

1. Increase the production rate or productivity by $13 \%(65$ vehicles per installer monthly) to meet the sales increase of 212,400 vehicles for the plan of the year 2008. This production rate was calculated by dividing the difference of the vehicle production for the two years by the vehicle production of the first year.

2. $\mathrm{P}=(\mathrm{P} 2-\mathrm{P} 1) /(\mathrm{P} 1)=(212,400-188,000) /(188,000)=13 \%$.
3. Enhance space utilization to be ( 71 vehicles per stall monthly) to avoid building new facilities.

4. Improve the Associates Engagement Index (Q12) by $60 \%$ to be at least 3.00, and enhance team work.

5. Reduce the variance in incentive for installers, and enhance team work.

6. Apply JIT principle, especially for parts supply.

7. Eliminate Muda causing time lost for installers, arranging tools, vehicles and collecting parts from the warehouse.

8. Improve the quality and apply quality control during the process.

9. Improve the planning for vehicles and parts.

10. Reduce the number of vehicles damaged by at least $50 \%$, and improve the layout and flow.

\section{TPS implementation/Kaizen}

The implementation of TPS was set by designing a timeline for the stages of TPS and Kaizen implementation in PIOC as shown in Table 4. The Kaizen Division of Toyota Motor Corporation (TMC) agreed to support Toyota Saudi Arabia in implementing TPS. TMC Kaizen Team gave theoretical and on the job Training to PIOC. PIOC started TPS trial implementation in plant 2 (Hilux). The result of implementing TPS was a $13 \%$ improvement in the production rate as will be explained later. The success of the TPS project in plant 2 encouraged PIOC to apply it in other plants. TMC Kaizen team visited PIOC in early 2008 and they appreciated the progress in TPS implementation. They made further recommendations in the areas of parts supply, 5S, production control boards, and safety.

The layout of the plant was changed from the old stall-type production, which is a push system, into a Toyota Production System (TPS) line, which is a pull system. The TPS is a line consisting of many stages each of which has 2 to 3 installers. The workers install the parts 
Citation: Abdulmouti H (2018) Benefits of Kaizen to Business Excellence: Evidence from a Case Study. Ind Eng Manage 7: 251. doi:10.4172/21690316.1000251

Page 11 of 15

\begin{tabular}{|c|c|c|c|c|c|c|c|c|c|c|c|c|c|c|}
\hline & \multirow[t]{2}{*}{ Plant } & \multicolumn{5}{|l|}{2007} & \multicolumn{8}{|c|}{2008} \\
\hline & & Aug & Sep & Oct & Nov & Dec & Jan & Feb & Mar & Apr & May & June & July & Aug \\
\hline $\begin{array}{l}\text { PIO coordination with TMC a support team arrived to Plant2, Jishuken } \\
\text { has been conducted by TMC team Tachindo \& Yamazumi, Takt Time } \\
\text { Calculation }\end{array}$ & 2 & & & & & & & & & & & & & \\
\hline $\begin{array}{l}\text { Start-up of the TPC line in Plant } 2 \text { for GL/GLX job process Design, } \\
\text { Documenting work instructions (standard procedures) for all installation } \\
\text { activities }\end{array}$ & 2 & & & & & & & & & & & & & \\
\hline $\begin{array}{l}\text { Enhancement of vehicles Process flow Mechanism (Drop once Pick } \\
\text { one). }\end{array}$ & 2 & & & & & & & & & & & & & \\
\hline $\begin{array}{l}\text { Enhancement of parts supply in bulk quantities on the TPS line. } \\
\text { Recycling parts Processes }\end{array}$ & 2 & & & & & & & & & & & & & \\
\hline $\begin{array}{l}\text { Start-up of the TPS line in Plant } 1 / 3 \text { for Process Design Documenting } \\
\text { work instructions (standard procedures) for all installation activities }\end{array}$ & $1 / 3$ & & & & & & & & & & & & & \\
\hline $\begin{array}{l}\text { Parts Layout Design \& Material Handling } \\
\text { Parts Supply Mechanism (Just in time). } \\
\text { Enhancing parts supply to the line, using trolleys, inclined shelves, } \\
\text { simple Trolleys Design }\end{array}$ & $1 / 2 / 3$ & & & & & & & & & & & & & \\
\hline $\begin{array}{l}\text { Manpower Training Manpower Evaluation \& Skill Matrix. Manpower } \\
\text { Internship \& On-job Training Certification 5s for shop floor \& - checklists, } \\
\text { standards, etc. }\end{array}$ & $1 / 2 / 3$ & & & & & & & & & & & & & \\
\hline Accurate Tools Preparation Standardizing Tools Control. & $1 / 2 / 3$ & & & & & & & & & & & & & \\
\hline $\begin{array}{l}\text { Production Control Sys. } \\
\text { Monitoring Boards and atomized data entry. }\end{array}$ & 1 & & & & & & & & & & & & & \\
\hline $\begin{array}{l}\text { Safety } \\
\text { Job safety analysis }\end{array}$ & $1 / 2 / 3$ & & & & & & & & & & & & & \\
\hline
\end{tabular}

Table 4: Phases and Stages of TPS and Kaizen Implementation Timeline in PIOC.

without interference in their movement and work. The vehicle and the trolley that carries the accessory items or parts move together from one stage to another till the final stage. Figure 12 shows the TPS line (accessorization area) including the stages for each step of part installation.

Initially, vehicles are parked in the pre-accessorized area near the TPS line (accessorization area) ready to be pulled into the TPS line as shown in Figure 13. Figure 14 shows the preparation area for the parts which are collected from the warehouse using JIT principle, and prepared for the daily production. These parts are carried in the trolley to the trolley buffer area. Figure 15 clarifies the new trolley design, which includes all the necessary parts for each vehicle. This is a big improvement for TPS using JIT. Figure 16 shows the trolley buffer area, where the trolley is parked ready to be pulled into the TPS line at the same time as the vehicle is pulled into the TPS line from the preaccessorized area. The principle of Just-in-time (JIT) parts supply is represented in Figure 17 where the vehicle and its trolley are parked in the TPS line. They are moved together along each step of the line until finished. Figure 18 illustrates the TPS implementation daily planning, which applies JIT principles to ensure that the vehicles arrive at the same time with the necessary parts to be pulled into the accessorization area of the TPS line. Figure 19 shows the final quality check which is a rope test to ensure that no accessorization comes loose.

While applying Kaizen, the seven classes of waste (Muda) were addressed to achieve the results as follows:

1. Overproduction: As the old stall-type production depended on a push system (with poor planning), extra space and an area for storing the vehicles was required. This was eliminated by applying TPS, saving cost, space and time by avoiding the unnecessary extra production of Muda items.

2. Waiting and delay: In the old stall-type production, it was difficult to control manpower movement and the installers used to wait till the drivers brought the vehicle to the accessorization area. Furthermore, they had to wait till parts were brought from

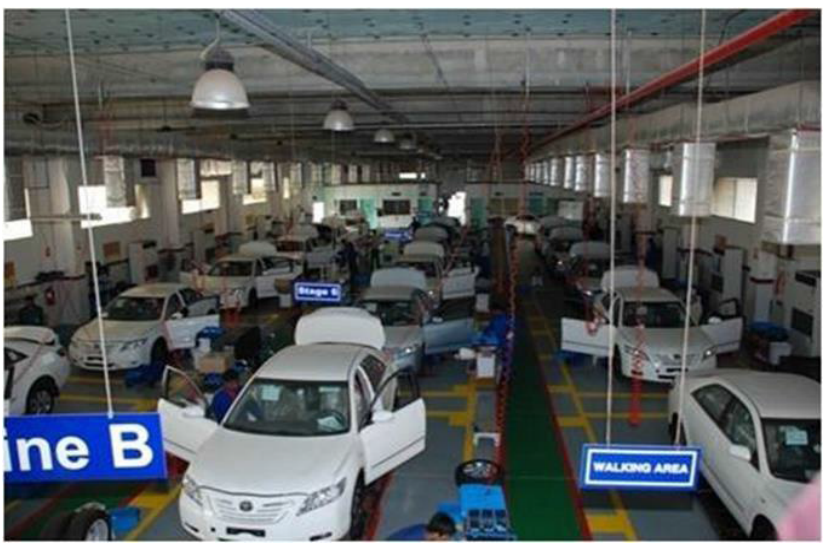

Figure 12: TPS line.

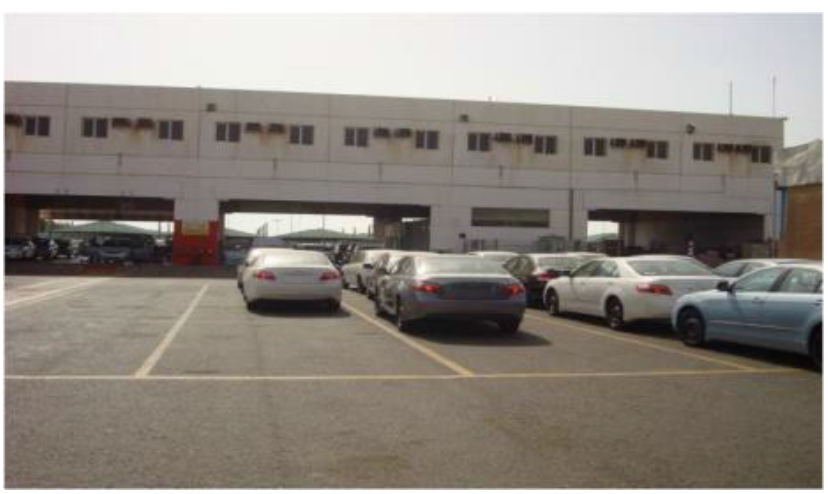

Figure 13: Pre-accessorized area.

the warehouse. This Muda adds no value to the process. By applying TPS, the vehicle and the trolley of the parts are pulled together into the TPS line, eliminating the waiting Muda. 

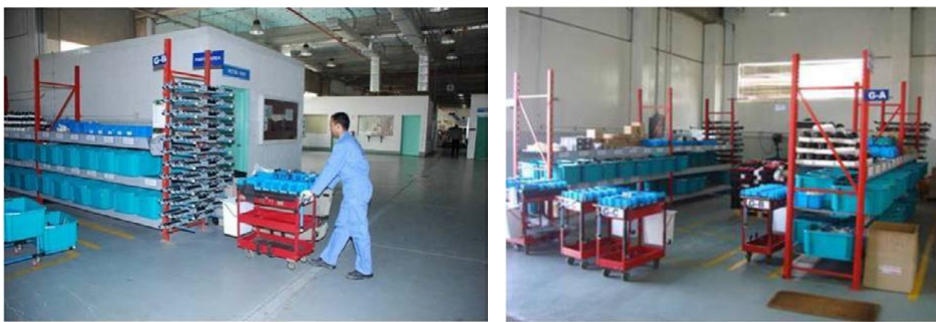

Figure 14: Preparation area for parts

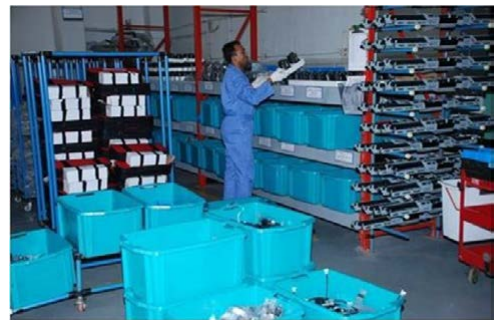

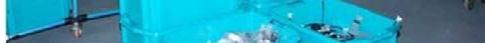

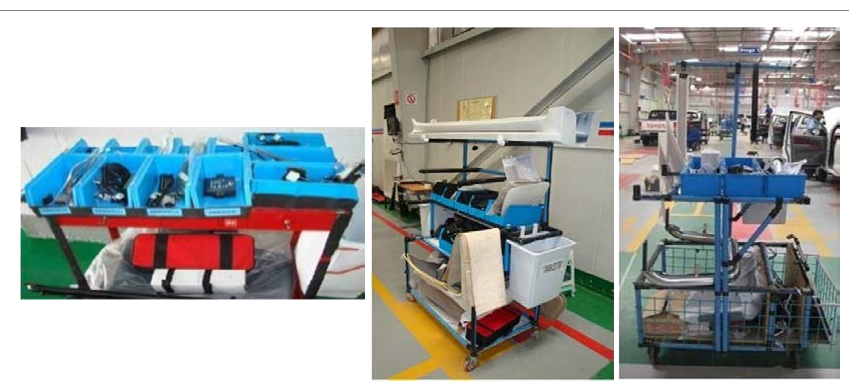

Figure 15: Trolley design/vehicle.

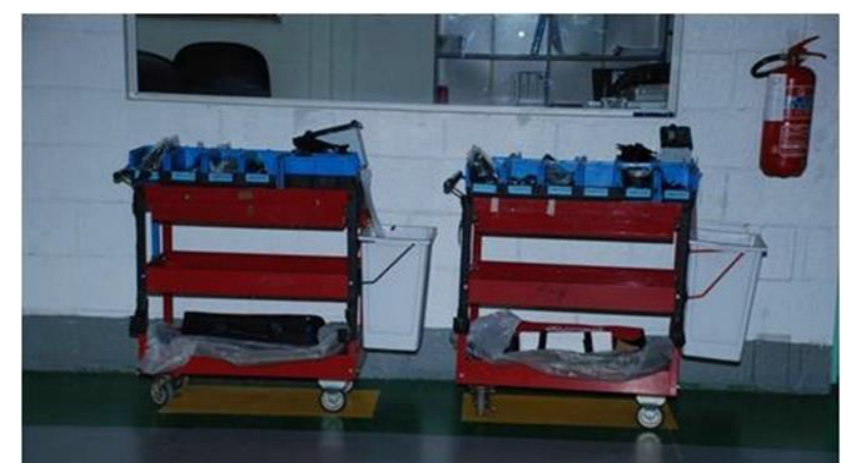

Figure 16: Trolley buffer area.

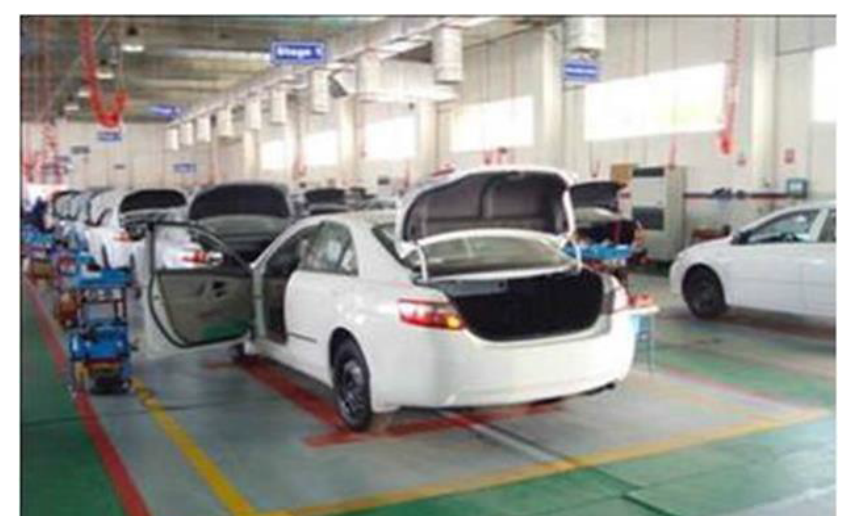

Figure 17: JIT parts supply.

3. Transportation: In the old stall-type production, the installers had to fetch the parts from the warehouse, which took time and meant extra cost. By applying TPS, the parts are prepared in the trolley for each vehicle.

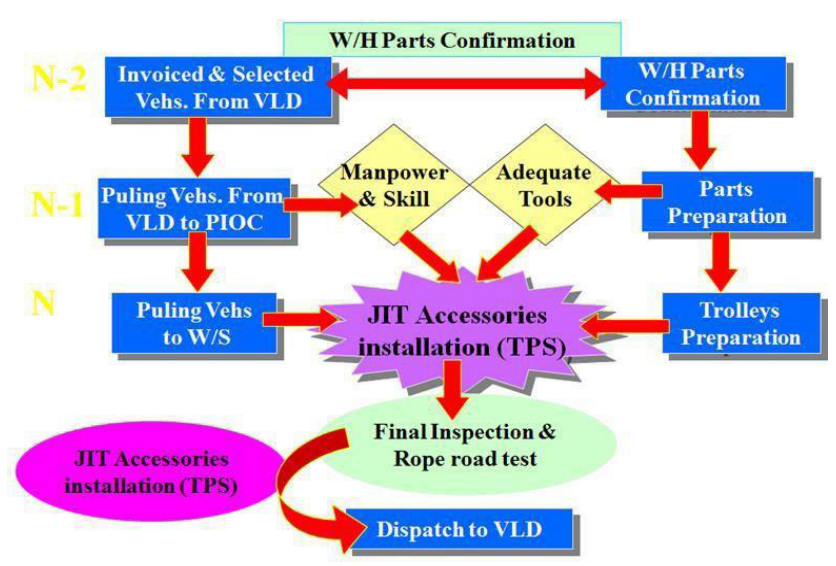

Figure 18: TPS implementation -daily planning.
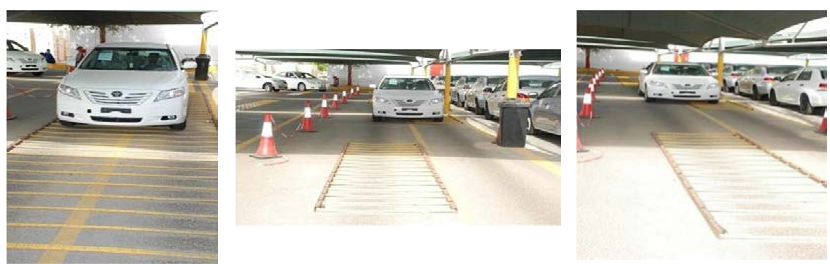

Figure 19: The final quality check (rope test).

4. Production of goods to a higher quality than needed: Many unnecessary processes were eliminated by applying TPS to avoid additional cost and time, especially for items that could not be sold.

5. Inventory or stock (un-recovered funds): The old stall-type production depended on a push system with poor planning, which required a storage area and equipment, management and maintenance to prevent deterioration, tying up much needed capital. All these issues were eliminated by applying TPS.

6. Wasted motion: In the old stall-type production, it was difficult to control manpower movement as the installers needed to collect parts from the warehouse which is considered unnecessary movement. By applying TPS the wasted motion was eliminated.

7. Defective parts repair/rejects/rework: In the old stall-type production, it was not easy to control the quality as the final check was undertaken by only one person. Many defective vehicles and accessory items or parts were found which had to be returned, resulting in extra cost for materials and repairs. 
TPS depends on applying quality control during the process, so the quality was improved and the defective vehicles were reduced.

\section{Main results of implementing the Kaizen principles}

The Kaizen target (which was set) was achieved after analyzing the problems, and then identifying the gap between the existing system and the TPS. Using the relevant Kaizen tools, including the Toyota Production System (TPS), 5S and the seven Muda, enabled understanding of the system and identification of critical problem areas.

Figures 20a-c present a comparison of the results in plant 1,2 and 3 before and after TPS implementation. The main technical results (Table 5) can be summarized as follows:

1. It is clear from this table that the monthly production rate (productivity) has increased form 50 vehicles per installer to 65 vehicles per installer, which is an increase of $13 \%$. Where the spaces were utilized more efficiently. Hence, the monthly space utilization increases from 63 Vehicle/stall to 71 Vehicles/stall.

2. The yearly plan of 212,400 for the year 2008 was achieved by implementing TPS and using the same facilities instead of building new

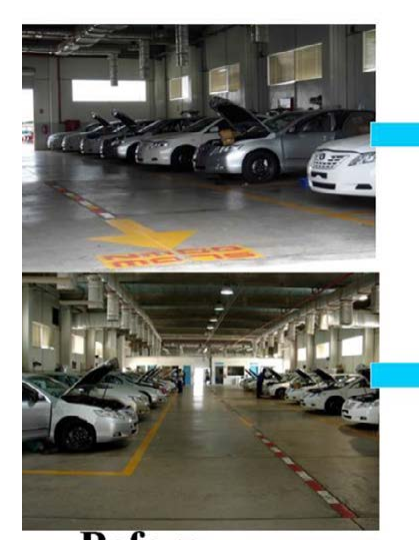

Before

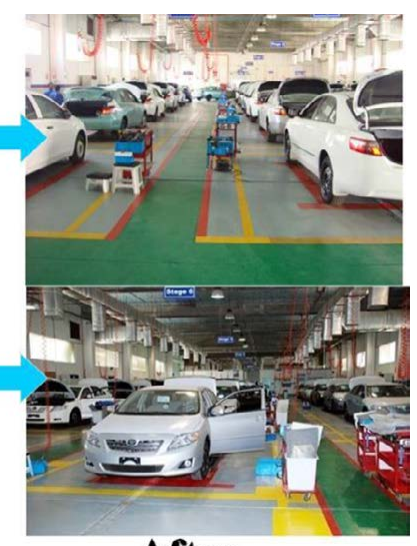

After
Figure 20a: A sample comparison of the results in plant 1 before and after TPS.

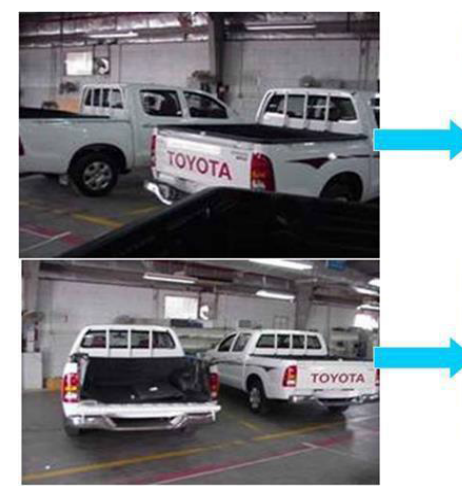

Before

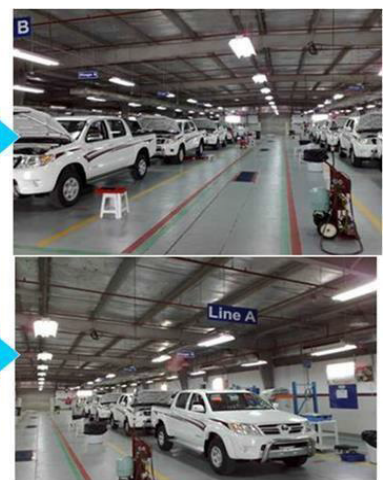

After
Figure 20b: A sample comparison of the results in plant 2 before and after TPS.

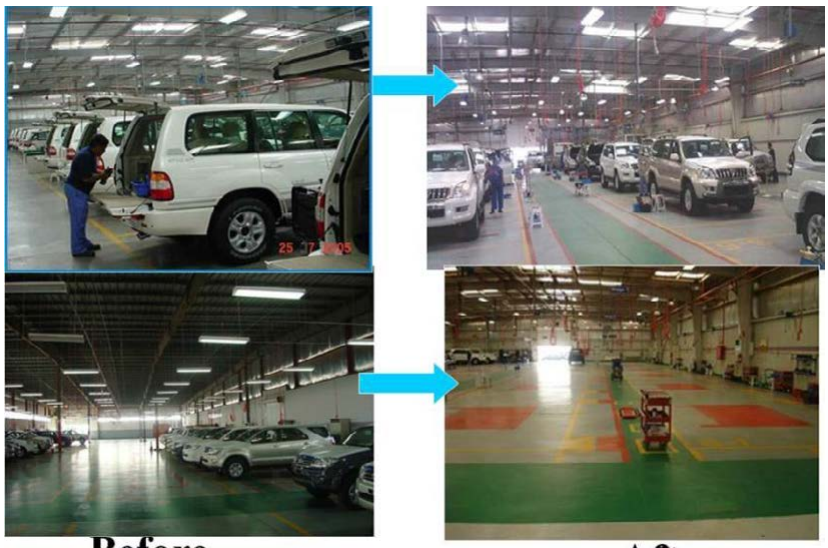

Before

After

Figure 20c: A sample comparison of the results in plant 3 before and after TPS

\begin{tabular}{|c|c|c|c|}
\hline Comparison & Stall-Type 2007 & TPS 2008 & Percentage \% \\
\hline $\begin{array}{c}\text { Monthly production rate } \\
\text { Monthly space } \\
\text { utilization }\end{array}$ & 63 vehicle/installer & 65 vehicle/installer & Increases 13 \\
\hline Q12 & 2.91 & 71 vehicle/stall & Enhances 13 \\
\hline Installers & $\begin{array}{c}\text { Required installer } \\
349\end{array}$ & Actual installers 275 & Decreases 27 \\
\hline Car damages & 480 & 115 & 76 \\
\hline
\end{tabular}

Table 5: A summary of the main technical results.

ones. Not investing in new facilities to meet the increase in the demand in the market was an important result of implementing Kaizen.

3. The Associates Engagement Index (Q12) results improved by $65 \%$ (from 2.91 to 3.11 ). This improvement was a great result of applying the TPS since the workers became one team with higher engagement, better communication and greater relationships.

4. The variance in incentive for installers was reduced to be almost equal as the production became based on team work rather than individual motivation. The idea of the 'man of the month' was removed from the policy of the plant to enhance team work.

5. All types of Muda causing time lost for installers, arranging tools, and vehicles were eliminated by using JIT parts supply and implementing the 7 Muda principles.

Moreover, controlling manpower movement becomes easier and more obvious as the installer does not need to collect parts from warehouse. Furthermore, a potential for inventory reduction was made obvious due to the use of Kanban system with just-in-time production.

6. Strict planning was implemented for the movement of vehicles and preparation of parts. The main objective of this important improvement in solid planning is to ensure that the vehicles arrive at the same time with the necessary parts to be pulled into the accessorization area of the TPS line.

7. Instead of hiring 37 new workers, the number of installers decreased by $27 \%$ from 349 to 275 .

8. There was an increase and clear improvement in the quality since the quality control is built into the processes and steps of the products of TPS. 
9. There was a reduction in the number of vehicles damaged due to the control of the layout and flow by $76 \%$ (from 480 in 2007 to 115 vehicles). All these resulted in improving the production line and this was appreciated and acknowledged by Toyota Motor Corporation.

\section{The financial impact of implementing TPS}

Table 6 summarized the saving in installers as a financial impact of applying TPS. It is clear that after TPS implementation, the daily planning was improved. Moreover, instead of recruiting 37 extra installers which are required to meet the increase in the demand in the market for the year 2008, the number of installers was reduced to 275 . The total saving in manpower is 74 which is the estimated number of installers required (349) minus the actual number of installers required for 2008 (275). This results in total savings in installers of about US\$ $1,332,000$.

Table 7 summarizes the saving by not having to build a new facility. It is clear from this table that by applying Kaizen including TPS, the total savings by not building new facilities is US $\$ 2,000,000$.

\begin{tabular}{|l|c|}
\hline Savings in Installers \\
\hline No. of installers in 2007 & 312 \\
\hline Forecasted No. of installers in 2008 / Stall-Type & 349 \\
\hline Actual No. of installers in 2008 /TPS & 275 \\
\hline Difference in No. of installers between 2007 and 2008 & 74 \\
\hline Monthly average package per installers (US\$ 1500) & US\$ 111,000 \\
\hline Total savings in installers in the year $\mathbf{2 0 0 8}$ & US\$ $\mathbf{1 , 3 3 2 , 0 0 0}$ \\
\hline
\end{tabular}

Table 6: The saving in installers

Savings by not building a new facility

Total No. of stalls for 74 installers to be accommodated in plants 75 Stalls

Total savings in building in 2008

US $\$ 2,000,000$

Note: min building cost is US $\$ 800 / \mathrm{m}^{2}$ (75 Stalls require $\left.2,500 \mathrm{~m}^{2}\right)$

Table 7: The saving by not building new facilities.

Therefore, the total savings by not employing new installers and building new facilities is US\$3,332,000. The increase in the annual output was about $13 \%$ (from 188,000 to 212,400 vehicles) for the year 2008.

\section{Conclusions}

The results of implementing the Kaizen principles at Port Installed Options Center (PIOC) in Toyota, Saudi Arabia were achieved by using relevant Kaizen tools including Toyota Production System (TPS), $5 \mathrm{~S}$ and the seven Muda. The Kaizen target was set after analyzing the problems and identifying the gap between the existing old stalltype system and the TPS. The interesting application of Kaizen and the results achieved reinforces the usefulness of the Kaizen tools to improve business excellence. The main results of the study can be summarized as follows:

1. Savings of about 3.33 million by not investing in new facilities needed to meet the increase in the demand in the market.

2. Total savings in installers of about $\$ 1.33$ million. Using the same facilities, it was possible to be more efficient by reducing the manpower needed by $27 \%$ (from 349 to 275 installers) instead of increasing the manpower by 37 to meet the increase in the demand in the market.

3. Annual output increased by about $13 \%$ (from 188,000 to 212,400 vehicles) and more efficient space utilization.
4. Improvement in the quality of the production since quality control is now built into each step of the process.

5. A 65\% increase (from 2.91 to 3.11) in the Associates Engagement Index (Q12). This reduced the variance in incentives for installers and enhanced team work with higher engagement, better communication and greater relationships.

6. A $76 \%$ reduction (from 480 to 115 vehicles) in the number of vehicles damaged due to the control of the layout and flow.

7. The potential for inventory reduction due to the use of the Kanban system with just-in-time production and a reduction in the number of vehicles damaged due to the control of the layout and flow.

8. Appreciation and acknowledgement by Toyota Motor Corporation of these resulting improvements in the production line.

\section{Acknowledgements}

1. I would like to express my gratitude and appreciation to a true leader, $\mathrm{Mr}$. Mohammed Jameel, the president of ALJ. Also I would like to thank the Director and staff of PIOC in ALJ.

2. The Author Hassan Abdulmouti used many facts and information as he was working as a member of Toyota Motor Corporation in Japan and in KSA.

3. I would like to express my gratitude to Mr. Andrew Downer for his help in proofreading this document.

\section{References}

1. Abdulmouti H (2010) Toyota Global Contents (Foundation and Principles) Jordanian Engineer Encyclopedia. Scientific Committee of Jordan Engineering Association in Jeddah (JEAJ).

2. Abdulmouti H (2012) Toyota Global Contents (Foundation and Principles). Alzah rowi Encyclopedia for Arab Engineer.

3. Abdulmouti $\mathrm{H}$ (2015) The Role of Kaizen (Continuous Improvement) in improving Companies' Performance: A Case Study. Proceedings of the 2015 International Conference on Industrial Engineering and Operations Management (IEOM), Dubai, UAE.

4. Liker JK, Meier D (2004) The Toyota Way Field book. A Practical Guid for Implementing Toyota's 4 Ps. The McG row-Hill.

5. Liker JK (2004) The Toyota Way. 14 Management Principles from The World's Greatest manufacturer. The Mc Grow Hill.

6. Imai M, Kaizen G (1997) A Commonsense, Low-Cost Approach to Management McGrow Hill

7. Cho F (2003) The 14 Principles of the Toyota Way: An Executive Summary of the Culture Behind TPS. From the Toyota Way document 2001, pp: 35-41.

8. Uitdehaag JCM (2011) The seven types of drug discovery waste: toward a new lean for the drug industry. Drug Discovery Today 16: 369-371.

9. Lander E, Liker JK (2007) The Toyota Production System and art: making highly customized and creative products the Toyota way. International Journal of Production Research 45: 3681-3698.

10. Liker JK (2003) The Toyota Way. New York: McG row-Hill.

11. Liker JK (2004) The Toyota Way 14 Management Principles from the World's Greatest Manufacturer McG row-Hill, New York, NY.

12. Liker JK, Morgan JM (2006) The Toyota Way in services: the case of lean product development. Academy of Management Perspectives 20: 5-20.

13. Liker JK, David M (2006) The Toyota Way Fieldbook. New York: McG row Hill.

14. Wakamatsu Y, Kodo T (2001) Toyota Way People and Production. Diamond Inc.

15. Lai SY, Tsai CH, Wei LY, Li RK, Lu MJ (2014) The Dilemma of Toyota Production System Implementation: A Case Study of Taiwan Machine Too Industries. International Journal of Academic Research in Accounting, Finance and Management Sciences 5: 1-12. 
Citation: Abdulmouti H (2018) Benefits of Kaizen to Business Excellence: Evidence from a Case Study. Ind Eng Manage 7: 251. doi:10.4172/21690316.1000251

16. TMC (2003) The Toyota Way in Sales and Marketing. Toyota Motor Corporation. Overseas Operation Group.

17. Abdulmouti H (2010) The Key to Japan's Competitive Success "Toyota Philosophy/Japanese Culture". Japan International Cooperation Center (JICE). Official Program of Japan-Saudi Arabia Academy Center (JSAAC) with KAUST (King Abdullah University of Science and Technology). Riyadh, KSA

18. Emiliani ML (2004) Improving business school courses by applying lean principles and practices. Quality Assurance in Education 12: 175-187.

19. Sakai Y, Sugano T, Maeda T (2007) Introduction of Toyota Production System to Promote Innovative Manufacturing. Fujitus Sci Tech J 43: 14-22.

20. Pardi T (2007) Redefining the Toyota Production System: The European side of the story. New Technology, Work and Employment 22: 2-20.

21. Chitre A (2010) Implementing the 5 S Methodology for Lab Management in the Quality Assurance Lab of a Flexible Packaging Converter. University of Wisconsin Stout. Master Degree thesis, p: 10.

22. Aoki K (2008) Transferring Japanese Kaizen activities to overseas plants in China. International Journal of Operations and Production Management 28 518-539.

23. Bullington KE (2003) 5 S for Suppliers. Quality Progress, pp: 56-59.

24. Michalska J, Szewieczek D (2007) The 5S methodology as a tool for improving the organization. Journal of Achievements in Materials and Manufacturing Engineering.

25. Withanachchi N, Handa Y, Karandagoda K, Pathirage PP, Tennakoon K et al (2007) TQM emphasizing 5-S principles: A breakthrough for chronic magerial constraints at public hospitals in developing countries. International Journal of Public Sector Management 20: 168-177.

26. Filip FC, Marascu-Klein V (2015) The 5 S lean method as a tool of industrial management performances. Modern Technologies in Industrial Engineering (ModTech2015). IOP Conf. Series: Materials Science and Engineering 95: 12-127.

27. Bargat SP, Mundhada N (2008) The 5'S Methodology as Tool for Improving the Organization. Certified International Journal of Engineering and Innovative Technology (IJEIT).
28. Abdulmouti H (2010) The Japanese culture, Toyota philosophy and Toyota way. Arab News.

29. Amasaka K (2002) New JIT: a new management technology principle at Toyota. International Journal of Production Economics 80: 135-144.

30. Black JT (2007) Design rules for implementing the Toyota Production System International Journal of Production Research 45: 3639-3664.

31. Bowen DE, Youngdahl WE (1998) Lean service: in defense of a production line approach. International Journal of Service Industry Management 9: 207-25.

32. Cua KO, McKone KE, Schroeder RG (2001) Relationships between implementation of TQM, JIT, and TPM and manufacturing performance. Journal of Operations Management 19: 675-694.

33. Fujimoto T (1999) The Evolution of a Manufacturing System at Toyota. Oxford University Press Inc., New York, NY, pp:129-172.

34. Jayaram J, Das A, Nicolae M (2010) Looking beyond the obvious: Unraveling the Toyota production system. Int. J. Production Economics 128: 280-291.

35. Mazur LM, Chen SJ, Prescott B (2008) Pragmatic evaluation of the Toyota Production System (TPS) analysis procedure for problem solving with entrylevel nurses. Journal of Industrial Engineering and Management 1: 240-268.

36. Towill DR (2007) Exploiting the DNA of the Toyota Production System. International Journal of Production Research 45: 3619-3637.

37. Yasuhiro M (1998) Toyota Production System. An Integrated Approach to Just In Time, $4^{\text {th }}$ edition, Norcross, GA: Engineering and Management Press.

38. Stewart TA, Raman AP (2007) Lessons from Toyota's long drive. Harvard Business Review 85: 74-83.

39. Masaaki Imai (1997) Gemba Kaizen: A Commonsense Approach to Continuous Improvement Strategy, 2nd ed, McG row-Hill, New York, NY, p:448

40. Schonberger RJ (2007) Japanese production management: an evolution with mixed success. Journal of Operations Management 25: 403-419. 